\title{
THE NEED FOR ORIENTATION TOWARDS NEWS MEDIA: REVISING AND VALIDATING A CLASSIC CONCEPT Förg Matthes
}

\begin{abstract}
The need for orientation is the most prominent contingent condition for agenda-setting effects. It provides a psychological explanation for why people engage in information seeking and why some people are susceptible to agenda-setting effects while others are not. The purpose of this paper is to present the development and empirical validation of a three-dimensional scale of need for orientation. Based on a review of previous measures, three dimensions of need for orientation are posited: The need for orientation towards issues, the need for orientation towards facts and the need for orientation towards journalistic evaluations. In a first step, the model is tested on a representative sample applying confirmatory factor analysis. After some modifications, the model is finally validated on another, independent sample. A series of studies demonstrate the psychometric properties of the measure and its construct validity with respect to related constructs. The theoretical utility of the construct and the measure of need for orientation are discussed.
\end{abstract}

The impact of the news media in setting the agenda by focusing the public's attention to key issues has long been a key topic in communication research. Since the ground breaking study by McCombs and Shaw (1972) during the I968 U.S. presidential election, more than 300 published articles have documented the agenda-setting function of the mass media (Dearing \& Rogers, I996). In short, agenda setting refers to the influence that the news media exert on the public's agenda by leading attention to those issues around which public opinion forms. In this process, agenda setting is not operative in a universal fashion as a plethora of limiting and contributing variables qualify this media effect. There are a number of studies that have examined these so-called contingent conditions of agenda setting. For instance, Demers, Craff, Choi, and Pession (I989) examined

All studies reported in this paper were part of a larger project funded by the German Research Council (No. KO I $854 / 2-\mathrm{I}$ ). The author would like to thank Matthias Kohring for providing the opportunity to collect these data, for his assistance, his support, and his valuable thoughts during the whole project.

The article was first submitted to IfPOR April 5, 2005. The final version was received August io, 2005. 
the influence of issue obtrusiveness, Wanta and $\mathrm{Wu}$ (1992) explored the role of interpersonal communication and Yagade and Dozier (I990) looked for the optimal time span for agenda-setting effects (for a recent review McCombs, 2004). Beside these variables, the so-called need for orientation 'is the most prominent of the contingent conditions for agenda-setting effects' (McCombs, 2004, p. 67). The need for orientation (NFO) provides a psychological explanation for why people engage in information seeking and why some people are susceptible to agenda-setting effects while others are not (McCombs, 2004; Shaw, McCombs, Weaver, \& Hamm, I999; Rössler, I999; Weaver, I977, I980; Weaver, McCombs, \& Shaw, 2004).

The theoretical concept of NFO was introduced by Maxwell E. McCombs and David H. Weaver (McCombs \& Weaver, I973; Weaver, I977, I980). It refers to the tendency of an individual to seek information about an issue in the news media. As previous research has demonstrated, active information seeking caused by a high NFO increases the susceptibility to agenda-setting effects (Weaver, I977, I980). Rooted in the tradition of the uses and gratifications approach (Atkin, I973; McCombs \& Weaver, I985), NFO is a core concept in agenda-setting research, and its impact on media effects has been demonstrated in several studies (e.g. Weaver, I980; Hügel, Degenhardt, \& Weiß, I989). After its final conceptualization by Weaver (1977, I980), however, NFO has been treated as a given concept without further explication. No research has ever systematically examined the concept in regard to its core theoretical and methodological assumptions. The purpose of this paper is, therefore, to probe the discussion on both, the theoretical conceptualization and the reliable and valid assessment of NFO. In a first step, the classic measurement of NFO in agendasetting research will be summarized. This summary is then followed by a critical discussion of theoretical and methodological shortcomings. These shortcomings suggest that there is a need to re-conceptualize the construct. Consequently, the development and validation of a new NFO scale will be presented. Three studies demonstrate the psychometric properties of the measure, its discriminant, structural and construct validity. Finally, both the limits of this approach and the perspectives for future research are outlined.

\section{THE NEED FOR ORIENTATION: DEFINITION AND OPERATIONALIZATION OF A CLASSIC CONCEPT}

In their seminal Chapel Hill study, McCombs and Shaw (1972) observed a relationship between the pattern of news coverage of the 1968 presidential election and the key issues of the campaign that the public perceived as important. More specifically, Ioo voters were asked to rank the most important political issues. Simultaneously, media coverage of five newspapers, two news magazines and two television evening news shows were analyzed. The results made history: The 
mass media influenced the voters' assessment of what they thought were the major issues of the campaign. It is important to note that the sample was solely based on undecided voters. Therefore, this study already implicitly embraced the concept of NFO, even though the authors did not clearly identify this psychological explanation for their results. One year later, McCombs and Weaver (I973; see Weaver, I980) introduced the notion of NFO as a theoretical concept into agenda-setting research. They found a significant correlation between NFO and media use for political information, which in turn was positively correlated with stronger aggregate agenda-setting effects. In another seminal study, Shaw and McCombs (I977) could replicate these findings: Voters who had already made up their mind earlier in the race were less susceptible to the agenda-setting effect compared to undecided voters. The lessons drawn from these studies were that the agenda-setting effect is dependent on the voters' NFO. This basic idea remained a fundamental backdrop in agenda-setting research throughout the last 30 years (Hügel et al., I989; McCombs, 2004; McCombs \& Weaver, I973; Rössler, I999; Rössler \& Schenk, 2000; Shaw et al., I999; Weaver, I977; I980; Wanta, I997; Weaver et al., 2004).

NFO can be considered as the starting point of research focusing on the psychological conditions of agenda setting. The idea was originally derived from cognitive utilitarian theories of motivation (Atkin, I973; Weaver, I977). Hence, NFO is conceived as a person's need to be familiar with one's surroundings (Weaver, I980). The concept builds on the assumption that individuals have the need to impose an adequate structure upon the perception of their environment (Weaver, 1977). Whenever confronted with an unfamiliar situation-such as judging new political candidates or complex political issues-people experience an NFO. This need for finding one's way through the jungle of politics leads to an increased orientation towards the mass media. The higher the NFO of a person is, the higher is information seeking behavior, media consumption, and susceptibility to the media's agenda setting.

NFO is defined by two lower order components (see Table I): relevance and uncertainty (Weaver, I980; McCombs \& Weaver, I985). Basically, a person will be influenced by the media if the issue being discussed is relevant, and if the person is unsure about her/his position on the issue. If an issue is perceived as irrelevant and the person is quite certain about it, there is only a low level of NFO.

TABLE I Components and levels of need for orientation as proposed by Weaver (1980)

\begin{tabular}{llll}
\hline & & \multicolumn{1}{c}{ Uncertainty low } & \multicolumn{1}{c}{ Uncertainty high } \\
\hline Relevance & Low & Low need for orientation & Moderate need for orientation \\
& High & Moderate need for orientation & High need for orientation \\
\hline
\end{tabular}


However, if relevance is low but uncertainty towards a topic is high, the NFO is believed to be moderate. When the relevance is high, the degree of perceived uncertainty determines the actual level of NFO: In case that uncertainty is lowgiven high relevance-people have the impression that they basically understand the issue which results in a moderate NFO. When both relevance and uncertainty are high, the NFO is also high, which leads to a comparatively high agenda-setting impact of the news media. Hence, there are three types of NFO: low, moderate, and high. In most studies, a three-point index is computed based on the two components, interest and uncertainty.

Procedures for the measurement of NFO have changed over time. In the original study by McCombs and Weaver (I973; see Swanson, I988) relevance was measured by combining interest in the campaigns, amount of discussion about political issues and politics in general. Uncertainty was gauged by the consistency of the respondents' votes in the past four presidential elections, strength of party identification, and the degree of certainty regarding the choice of a presidential candidate. In contrast, Weaver (I980; also Hügel et al., I989) measured relevance with an ordinal 4-point variable reflecting the degree of interest in the campaign. Uncertainty was assessed by a voting intention scale, that is those respondents who already knew what they were going to vote were considered to have had a 'low' degree and those unsure of their vote had a 'high' degree of uncertainty. Whereas in most studies interest was measured as issue independent (i.e. general political interest), Rössler (I 999) suggested an issue-specific operationalization combining measures of political interest and uncertainty related to a respective issue.

Taken together, studies incorporating NFO as a predictor of agenda-setting effects have been successful in most instances (Swanson, I988; Winter, I98I). For example, McCombs and Weaver (1973) found a significant correlation between NFO, media use for political information, and agenda setting. Similarly, Weaver, Graber, McCombs, and Eyal (I98I) reported that - compared to voters with a low NFO-voters with a high NFO were paying more attention to the content of the mass media near the end of the campaign, and they were more likely to have issue agendas similar to the media's agenda. The pattern of results of a study by Wanta (I997) revealed further evidence for this line of reasoning: There is a significant positive correlation between political interest and susceptibility to agenda setting. All these studies suggest that 'the need for orientation concept is one of only two contingent conditions (the other is the simple amount of media exposure) for which there is totally unambiguous evidence' (Winter, I98I, p. 239). However, other studies based on individual level analysis showed highest agenda-setting effects at moderate levels of NFO. For instance, Schönbach and Weaver ( 1985 ) reported that persons with low interest and high uncertaintyi.e. moderate NFO — showed the strongest agenda-setting effects. Studies that have only used an interest measure have shown similar results (Winter, I98I). Likewise, in Rössler's ( I999) individual level study, NFO did indeed stimulate 
media use but did not lead to significant agenda-setting effects. In another agenda-setting study, Peter (2003) reports a significant negative correlation between the NFO and the importance that individuals attach to the issue of European integration.

\section{TOWARDS REFINING THE CONCEPT OF NEED FOR ORIENTATION}

Notwithstanding widespread faith in the utility of the NFO construct, certain of its conceptual aspects pose problems for agenda-setting scholars (Swanson, I988). First of all, studies on NFO have often been inattentive to the difference between the two types of moderate NFO. The need for distinguishing between these two types may be reflected in some results mentioned earlier, showing greater agenda-setting effects for people with moderate levels of NFO (Schönbach $\&$ Weaver, 1985 ; Swanson, I988). McCombs and Weaver (1985, p. 98 ) also admit that there 'is still an argument to be made that the two moderate need for orientation conditions are different qualitatively, if not quantitatively'. To date, there is no study comparing the two moderate types of NFO. On a conceptual level, it can be argued that both types are indeed different. It may be possible that a person who feels the issue is highly relevant but is also quite certain what to think about it has a stronger NFO than a person who feels quite uncertain about an irrelevant issue. In other words, if an issue is not relevant, it may not matter how certain one feels about it. Therefore, the concept of relevance may be a stronger indicator of NFO than the concept of uncertainty. More recently, McCombs (2004) has also posited that relevance is the initial and uncertainty the subsequent defining condition of NFO. This means, if relevance to the individual is low, NFO is also low. Perhaps even more importantly, relevance and uncertainty can be seen as lower order concepts, not as dimensions. In other words, relevance and uncertainty are predictors, not components of NFO-they are supposed to lead to NFO. Conceived this way, it can be stated that NFO was only measured indirectly in all previous studies.

In addition to these theoretical concerns, some problems have surfaced in how researchers have operationalized the concept of NFO. Usually, NFO is measured with an ordinal variable consisting of three categories. From a methodological point of view, ordinal scale variables have several weaknesses. Beside the fact that ordinal measures prevent researchers from using advanced statistical analysis methods, the intervals between the three categories are not necessarily equal. Therefore, the measure can only provide a rough mapping of the sample currently under investigation. Furthermore, measuring NFO with only one ordinal item makes it impossible to secure reliability. Up to date, the reliability of NFO measures has not been established in any study. Likewise, the construct validity of NFO remains another unresolved issue. Following this train of thought, it 
becomes evident that there is a need for a metric assessment of NFO with several items enabling researchers to establish criteria of reliability and validity.

Another related shortcoming prevalent in the literature is that NFO is based on a general interest in politics as an indicator of relevance (Rössler, I999). That misses the evident fact that relevance varies between issues. As agenda setting refers to the shift of salience between individual issues, NFO should also be measured separately for each issue under examination (Rössler, I999). Moreover, the lack of significant findings in some studies may also be attributable to the fact that NFO towards the media and NFO towards other people have not been separated in previous research. A high NFO_as conceptualized in previous studies - will stimulate both media use and interpersonal communication. This is important because the impact of NFO on the agenda-setting function of the mass media can be diminished by interpersonal communication (Erbring, Goldenberg, \& Miller, I980; Wanta \& Wu, I992). These insights suggest that there is a need to re-conceptualize and re-operationalize the concept of NFO. However, pointing out these conceptual and methodological concerns in no way suggests that NFO is a problematic concept itself. In contrast, we suggest refining the concept in order to provide a richer understanding of the relationship between NFO and agenda setting.

Based on the review outlined in the last section, we posit five premises for the operationalization of NFO. First of all, although relevance and uncertainty might lead to NFO, these two concepts are seen as lower order constructs that do enable a prediction but not a direct measure of the construct. Therefore, we posit that NFO must be measured with more direct indicators expressing the motivation of respondents to turn to the news media in order to fulfill their NFO. Second, the motivation to turn to interpersonal communication should be separated from the NFO towards news media. Therefore, items measuring NFO should tap the notion of orientation towards the mass media, not a general interest towards a topic. Third, since the NFO measure is meant to predict agendasetting effects in regard to specific issues, items should be formulated for specific issues only. Fourth, in order to establish criteria of reliability and validity, it is recommended to use several metric items in the measurement procedure. Fifth and last, the NFO measure should be developed in a scale construction process that provides evidence for the factorial, discriminant, and construct validity.

Beside these premises, the concept of NFO is still understood as a motivation to turn to the mass media for orientation. As McCombs (2004, p. 54) puts it, $\mathrm{NFO}$ 'is a psychological concept, which means that it describes individual differences in the desire for orienting cues and background information'. Although people might have a general tendency to score high or low on NFO across various issues, NFO is understood to be issue-specific. This means, depending on the issue and on the amount of general interest and uncertainty, NFO may vary and is, therefore, not a trait variable. 
Moreover, considering recent efforts in broadening the concept of agenda setting to second level agenda setting (McCombs, 2004; McCombs \& Ghanem, 200I; McCombs, López-Escobar, \& Llamas, 2000; López-Escobar, Llamas, \& McCombs, I998), it makes sense to extend the concept of NFO as well. In recent years, the emergence of the second level of agenda setting has prompted a deeper understanding of agenda-setting effects. The second level of agenda setting refers to a process similar to first level: Instead of examining an agenda of issues, this line of research investigates an agenda of attributes. The two levels of agenda setting also imply different types of information processing. While first level agenda setting involves issues, second level agenda setting refers to more specific characteristics of objects. These objects can be sub-issues or specific aspects and selections of issues (cognitive attributes; see McCombs \& Ghanem, 200I). Furthermore, the second level of agenda setting also incorporates specific evaluations or journalistic assessments of issues (affective attributes; McCombs \& Ghanem, 200I; McCombs et al., 2000).

Based on that, three levels of an issue can be distinguished: the issue itself (i.e. what to think about), specific aspects or frames of an issue (i.e. how to think about) and, finally, specific journalistic evaluations (i.e. what to think). This view also corresponds to the seminal study by Benton and Frazier (1976) who tried to extend the agenda-setting function by examining three levels of people's information holding. Furthermore, there is a strong connection to two subdimensions of information seeking motivations proposed by Atkin (1973). Atkin-whose work was also cited in Weaver's (I980) seminal study—suggested, first, a need for surveillance information that is quite similar to the NFO towards an issue and, second, a need for guidance information that matches the need for orientation towards journalistic evaluations.

Adopting these developments in agenda-setting theory to the NFO concept, we can also conceptualize NFO at several levels. First of all, based on the first level of agenda setting, there is an NFO towards the issue itself. This dimension corresponds to the need of surveillance of issues or topics. Recipients will focus on those topics and events that are relevant to them and therefore they have a need to observe the emergence of relevant topics in the news media. Second, there can be an NFO in regard to specific aspects or several thematic sides of an issue. This dimension concerns the selection of facts or background information pertaining to a topic that has already been selected. It is therefore the way in which an issue is contextualized or framed. Although scholars differ on the exact definition and theoretical boundaries between second level agenda setting and framing (McCombs \& Ghanem, 200I; Scheufele, I999, 2000; Takeshita, 2006), most researchers do agree that media framing refers to the emphasis of certain aspects or attributes of an issue. This is exactly what is meant by this dimension. Thus, a person with a high NFO towards specific aspects of an issue wants to know about several subaspects or frames of an issue. For instance, what aspects of an issue are important and how are these aspects woven together? Third and last, we posit an NFO 
towards journalistic evaluations. We assume that - dependent on the issueindividuals differ in their NFO towards journalistic assessments. These evaluations can be stated either explicitly or implicitly. Explicit evaluations are emphasized statements on what to think about an issue or what to do in a specific situation, especially in the commentary structure of an article or news report. In other words, they offer advice as well as assessments and appeals for action. Implicit evaluations refer to the selection of specific information that represents an assessment.

Taken together, we can conclude that a multi-dimensional theoretical framework of agenda setting leads us to a distinction between three levels of NFO: (I) NFO towards an issue; (2) NFO towards specific aspects or frames of an issue; and (3) NFO in regard to journalistic evaluations. Our assumption is that in their interaction, these three dimensions constitute the construct of NFO.

We conducted three surveys to operationalize and validate a new measure of NFO based on these three dimensions. All studies were part of a larger project dealing with trust in news media (Kohring \& Matthes, 2004). In order to establish and empirically confirm a standardized concept of NFO, a confirmatory instead of an explorative approach - as is still common in many scale developments in the communication sciences (Holbert \& Stephenson, 2002) - is needed. Thus, the data were analyzed by confirmatory factor analysis, which allows hypotheses about the structure of concepts to be represented. The first study served as an initial test for the specific factor model of NFO. It was, however, expected that the factor model would require some modifications in order to improve model fit. After these modifications, the new structure was to be tested and validated in the first wave of an independent panel study (Study 2). Finally, the second wave of the panel study (Study 3) aimed at a construct validation of the NFO scale-all variables needed for a construct validation were measured in this survey.

\section{STUDY I: MODEL DEVELOPMENT}

Based on the theorizing in the previous section, it can be hypothesized that NFO towards news media is a three-factorial construct with the positively correlated dimensions 'orientation towards issues', 'orientation towards facts', and 'orientation towards journalistic evaluations'. This hypothesis seeks to provide evidence that the correlational structure of the measure is consistent with the hypothesized three-dimensional structure of the construct. The postulated three factorial model should therefore be superior to any other alternative model. This can be tested with structural equation models.

\section{Method}

We conducted several pilot studies, the results of which will be briefly summarized in the following section. In order to operationalize the proposed factor 
model, it seemed wise to combine a qualitative with a quantitative procedure (Tashakkori \& Teddlie, I998). This combination optimizes item phrasing and stimulates hypothesis development. Consequently, the first pilot study encompassed qualitative interviews with 27 persons. The persons could choose a political issue they liked to talk about. Open questions were meant to explore whether the interviewees did indeed differentiate between the three factors of NFO. In fact, there were many statements by the interviewees that clearly demonstrated the usefulness of this distinction. Furthermore, the interviews were used to generate an item set of ${ }_{5} 5$ statements. Based on that, a standardized questionnaire was developed which underwent a cognitive pretest $(N=20)$ that was carried out by the Center for Survey Research and Methodology (ZUMA) at the University of Mannheim (Germany). Furthermore, the items were applied to another pretest which was a standardized survey with a sample of Ioo graduate and undergraduate students (59 percent female; age: $M=\mathbf{2 2 . 8}$, $S D=2.5$ ). In this study, exploratory factor analysis provided essential support for both the theoretical concept and the selection of items. Moreover, the study enabled the improvement of individual item phrasing. Based on these pilot studies, four items were formulated for the factor NFO towards issues, three items for the factor NFO towards facts and, finally, also four items for the last factor, NFO towards evaluations.

The main survey was conducted by the Center for Socio-scientific Surveys, University of Duisburg (Germany). The questionnaire was programmed for an application of CATI (Computer Assisted Telephone Interview). In order to avoid order effects, the questions were rotated at random. For the sampling procedure, a method was applied that would facilitate a simple random selection of households with telephone connections in consideration of non-listed numbers (Gabler \& Häder, 2002). The survey took place in Schwerin (Germany) in June 2002. The questions were answered on a seven-point scale with an additional 'don't know' option. The topic of the survey was the issue of unemployment-the major issue in the German news media throughout these months. The survey in Schwerin encompassed 5 Io interviews. According to the standard definitions of the American Association for Public Opinion Research (2000), the minimum response rate was $R_{\mathrm{I}}=. \mathrm{I}_{3}$. Extremely short interviews and those displaying an extremely monotonous answering pattern of the items were excluded. The final sample therefore encompassed 476 interviews; $5 \mathrm{I} .3$ percent of the interviewees were female, the average age was 48.00 years $\left(S D={ }_{1} 8.55\right)$. The sample had a slight above-average number of higher educational degrees.

As stated above, the factorial structure of NFO can be tested with confirmatory factor analysis (CFA), a structural equation modeling technique. CFA has taken on a major role in scale development as it can greatly enhance the confidence in the structure and the psychometric properties of a new measure 
(Holbert \& Stephenson, 2002; Noar, 2003). In CFA, it is possible to represent hypotheses about the factorial structure of constructs (Bollen, I989). It requires the researcher to specify an explicit model or several competing models of how all variables are related to the hypothesized latent factors. Furthermore, CFA permits comparative model testing to establish whether the a priori model fits the data better than other plausible competing models. The data were analyzed with CFA using maximum-likelihood (ML) parameter estimation and were tested for their distribution (see Kline, I998; West, Finch, \& Curran, I995). The average amount of missing values was below 0.05 percent. Those were replaced with means. In order to evaluate model fit, the following criteria were incorporated (Arbuckle \& Wothke, I999; Kline, I998): the chi-square value divided by the number of degrees of freedom, the Goodness of Fit Index (GFI), the Adjusted Goodness of Fit Index (AGFI), the Root Mean Square Error of Approximation (RMSEA). The variances of the latent factors and the coefficients of the regression of the error terms were fixed to one, while the latent factors were hypothesized to correlate.

\section{Results}

We hypothesized that NFO is a three-factorial construct with the positively correlated dimensions 'orientation towards issues', 'orientation towards facts', and 'orientation towards journalistic evaluations'. This factorial model is tested in a first step applying confirmatory factor analysis. The results show, that although the fit indices for the whole structural equation model are good, the indicators of two variables are not satisfactory. Based on the modification indices, these two variables had to be eliminated. ${ }^{1}$ The resulting modified model is depicted in Figure $\mathrm{I}$. The precise item phrasing, its factor loadings, and indicator reliabilities are shown in Table 2 . The fit indices for the modified model are acceptable: $\chi^{2} /$ $d f=3.4 ; \mathrm{GFI}=.96 ; \mathrm{AGFI}=.93$, and $\mathrm{RMSEA}=.07$. As expected, there are high correlations among the factors: The dimension NFO towards issues correlates with a coefficient of $r=.88$ with the dimension NFO towards facts and with a coefficient of $r=.70$ with the dimension NFO towards evaluations. There is a correlation of $r=.74$ between NFO towards facts and NFO towards evaluations. Also because of the high correlations, the model was tested against two alternative models ('nested model comparison'; Arbuckle \& Wothke, I999): first, a single factor model, which contains one factor that explains all items, and second, a two-factor model in which the two factors with the highest correlation were matched (orientation towards issues and towards facts). By means of nested model comparison, we can run a test to discover which theoretical model has the

\footnotetext{
${ }^{1}$ These were the items 'I always want to be up to date for this topic' and 'I don't care what journalists say about this topic.'
} 
FIGURE I Measurement model for need for orientation towards news media

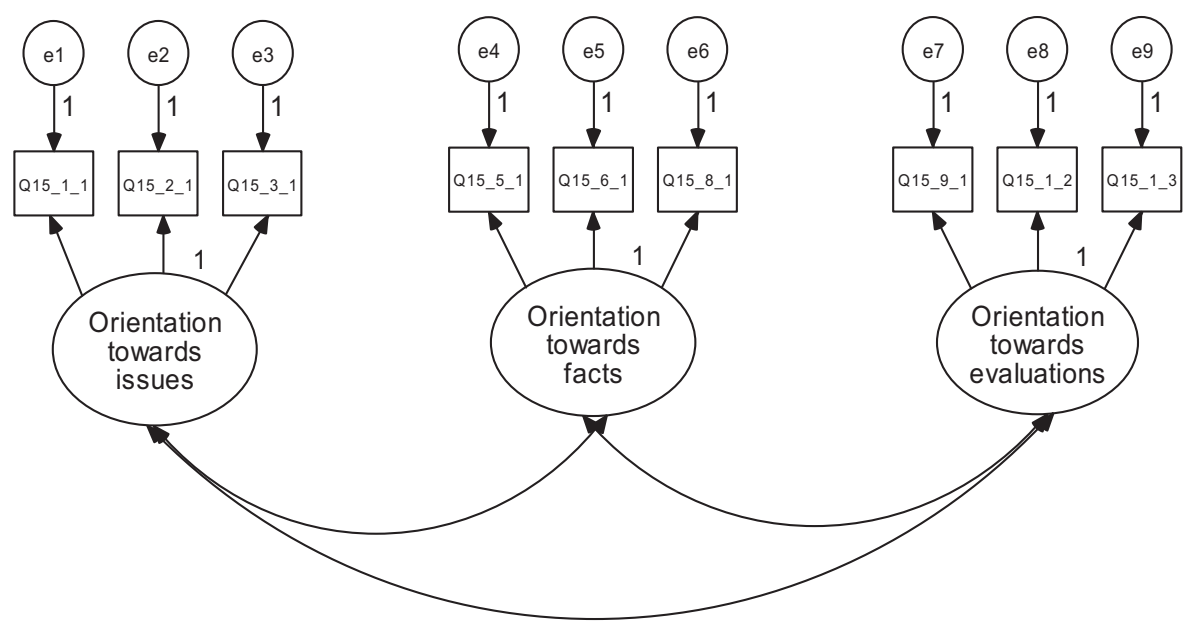

best fit to the data. In other words, it is tested whether NFO is one-, two- or three-dimensional. ${ }^{2}$ As a result, the original three-factor model as depicted in Figure I fits the data significantly better than the two alternative models. This result strongly supports the discriminant validity of all the three factors. Therefore, our hypothesis can be considered as verified: NFO towards news media consists of the three factors 'orientation towards issues', 'orientation towards facts', and 'orientation towards journalistic evaluations'.

\section{Discussion}

Study I offers clear support for the notion of three NFO dimensions: NFO towards issues, NFO towards facts and NFO towards journalistic evaluations. These results correspond to the seminal distinction between three levels of information holding as proposed by Benton and Frazier (1976). First, there is an NFO towards the issue itself. This dimension embraces the need of surveillance of issues or topics. Recipients will focus on those topics that are relevant to them and therefore they have a need to observe the emergence of relevant topics in the news. More specifically, this factor describes the need of individuals to keep informed about recent developments of what is going on. At the second level, there is an NFO in regard to specific aspects or several thematic sides of an issue, that is an orientation to what exactly is discussed. This dimension concerns the selection of facts or background information. A person with a high NFO towards

\footnotetext{
${ }^{2}$ When conducting confirmatory factor analysis and nested model comparison, an additional exploratory factor analysis is not really necessary. Testing the number of factors with nested model comparison is a superior technique compared to the Eigenvalue rule of thumb in exploratory factor analysis.
} 
TABLE 2 Factor loadings $(\lambda)$ and squared multiple correlations (SMC) for the confirmatory factor analysis model in Studies $I$ and 2

\begin{tabular}{|c|c|c|c|c|c|}
\hline \multirow{2}{*}{$\begin{array}{l}\text { Need for } \\
\text { orientation }\end{array}$} & \multirow[t]{2}{*}{ Items } & \multicolumn{2}{|c|}{ Study I } & \multicolumn{2}{|c|}{ Study 2} \\
\hline & & $\lambda$ & $S M C$ & $\lambda$ & $S M C$ \\
\hline \multicolumn{6}{|c|}{... towards issues } \\
\hline & $\begin{array}{l}\text { I want to be instantly informed } \\
\text { about recent developments. }\end{array}$ & .82 & .68 & .80 & .64 \\
\hline & $\begin{array}{l}\text { It is important for me to observe } \\
\text { this issue constantly. }\end{array}$ & .79 & .63 & .78 & $.6 \mathrm{I}$ \\
\hline & $\begin{array}{l}\text { I would like to hear something } \\
\text { about the issue every day. }\end{array}$ & .64 & .40 & .63 & .40 \\
\hline \multicolumn{6}{|c|}{... towards facts } \\
\hline & $\begin{array}{l}\text { I want to know many different } \\
\text { sides about that topic. }\end{array}$ & .77 & .59 & .70 & .49 \\
\hline & $\begin{array}{l}\text { I would like to be thoroughly } \\
\text { informed about specific details. }\end{array}$ & .75 & .56 & $.8 \mathrm{I}$ & .65 \\
\hline & $\begin{array}{l}\text { For this topic, I expect detailed } \\
\text { background information. }\end{array}$ & .74 & .55 & .67 & .45 \\
\hline \multicolumn{6}{|c|}{$\begin{array}{l}\ldots \text { towards } \\
\text { evaluations }\end{array}$} \\
\hline & $\begin{array}{l}\text { I attach great importance to } \\
\text { commentaries on this topic. }\end{array}$ & .82 & .67 & $\cdot 77$ & .60 \\
\hline & $\begin{array}{l}\text { It is interesting to see how several } \\
\text { journalists comment on that issue. }\end{array}$ & .64 & $.4 \mathrm{I}$ & $\cdot 57$ & .33 \\
\hline & $\begin{array}{l}\text { Whenever appropriate, journalists } \\
\text { should state their opinions. }\end{array}$ & .52 & .27 & .53 & .28 \\
\hline
\end{tabular}

Note: The items were introduced with the following two sentences: 'Please think about the media coverage on the issue unemployment. The following statements deal with what you generally expect from media coverage on unemployment.'

facts wants to know about several sides and frames of an issue and does expect detailed background information. It is not just to be informed which topics or issues are important, but to thoroughly know what is being discussed and where the crucial arguments lie. At the third level, there is an NFO towards journalistic evaluations. Evaluations offer advice as well as assessments of and appeals for action in regard to a specific problem. Individuals with a high NFO towards evaluations attach importance to what journalists say about an issue, that is how they comment on the problems at hand.

However, the results of Study I must be interpreted with some caution. Scale construction is an iterative process which closely combines the development of theory and data (Clark \& Watson, I995, p. 3I I; John \& Benet-Martínez, 2000, p. 363 ). On the basis of a theoretical model, items are developed and assigned to the respective factors. The factorial structure is examined, improved, tested on 
other data and, if necessary, modified. This process is only (temporarily) completed, when a data-guided developed model has undergone a cross-validation analysis (Breckler, I990, p. 267). In fact, the final factor model in Study I was developed, at least in part, in a data-driven process. This makes a cross validation on an independent sample necessary. Cross validation is an essential step in the scale construction process because the elimination of several items to improve model fit — as it was conducted in Study I — must be recognized as a data driven process which inhibits generalization to other samples: '[T]he specification search process is inherently susceptible to capitalization on chance in that idiosyncratic characteristics of the sample may influence the particular modifications that are performed' (MacCallum, Roznowski, \& Necowitz, I992, p. 49I; also see Gerbing \& Hamilton, I996, p. 71; Kline, I998, p. 216). The test of the factorial model on an independent sample that provides evidence for the structural validity of the construct will be described in Study 2.

\section{STUDY 2: STRUCTURAL VALIDITY}

As outlined above, the data-guided procedure used in modifying the structural equation model requires the factorial structure to be validated on an independent random sample. Therefore, it is hypothesized that the model developed in Study I can be validated in another survey. In terms of structural equation modeling, this means that the model should provide a perfect fit and that no further modifications are necessary.

\section{METHOD}

The second survey took place in Berlin (Germany) in June 2002 in precisely the same manner as Study I. The topic of the survey was again the issue of unemployment. The Berlin survey is the first wave of a two-wave panel study, the second wave of which is described in Study 3. The survey covered 8I2 interviews, of which 777 cases were finally selected in the same manner as described for Study I. According to the standard definitions of the American Association for Public Opinion Research (2000), the minimum response rate was RRI $=. I_{4}$. A proportion of 54.2 percent of the participants were female; the average age was 46.I 8 ( $S D=$ I 8.19$)$ years. As in Schwerin, an above-average number of participants in this group had attained high educational degrees. The data were again analyzed with CFA using ML parameter estimation. The average amount of missing values was below 0.05 percent, they were replaced with means. However, replacing missing values with means can be problematic because it builds on the completely-missing-at-random assumption, which is hard to hold. Therefore, in order to prove the stability of results, this time the factor model will additionally be estimated with Full Information Maximum Likelihood (FIML) (Enders \& Bandalos, 200I). 


\section{RESUlts}

The fit indices that were calculated for the postulated model are highly satisfactory: $\chi^{2} / d f=2.4, \mathrm{GFI}=.97, \mathrm{AGFI}=.95$ and $\mathrm{RMSEA}=.06$. The scale could thus be validated with an independent random sample. Table 2 above also lists the factor loadings and the indicator reliabilities of the items in Study 2.

The often criticized (Clark \& Watson, I995, p. 316) but nonetheless common coefficient Cronbach's Alpha is satisfactory for the three factors: orientation towards issues, $\alpha=.79$; orientation towards facts, $\alpha=.90$; and orientation towards evaluations, $\alpha=.70$. The model was also tested with FIML estimation which produces reliable estimated values under the less strict missing-at-random assumption (Enders \& Bandalos, 200I). Again, the fit indices are satisfactory: $\mathrm{CFI}=.97, \mathrm{RMSEA}=.06$.

However, this result should be interpreted with some caution because ML estimation needs relatively stringent distributional assumptions (e.g. multivariate normality). As there are several NFO items that show significant deviations from normal distribution (i.e. positive skewness), problems with ML estimation can occur. Monte Carlo studies have shown that, with increasing non-normality, ML estimation leads to inflated results (Curran, West, \& Finch, I996; Gold, Bentler, \& Kim, 2003). For example, underestimation of standard errors of parameter estimates is likely to occur in such cases (West et al., I995). The remedy to this problem is the use of alternative estimation procedures such as the asymptotically distribution free (ADF) estimation. However, ADF estimation requires large sample sizes to produce stable estimates (Muthén \& Kaplan, I992). Several authors recommend a sample size of at least I,ooo cases for the adequate performance of the ADF-based $\chi^{2}$-statistic (Wegener \& Fabrigar, 2000, p. 422; West et al., I995, p. 68). Therefore, in order to test the robustness and appropriateness of the results with an alternative ADF procedure, the Schwerin survey and the first panel wave of the Berlin survey were matched. This results in a data set with I,2 I 4 respondents, enough to go for ADF estimation. As a result, the factorial model as depicted in Figure I turns out to be completely robust $\left(\chi^{2} / d f=2.8, \mathrm{GFI}=.96, \mathrm{AGFI}=.93\right.$ and $\left.\mathrm{RMSEA}=.05\right)$; no inflation of estimates can be detected for any of the coefficients.

\section{Discussion}

The second study gives convincing support for the structural validity of the NFO measure. The factor model could be validated on an independent random sample. Furthermore, the stability of this result could be established by alternative estimation techniques. These insights suggest that the scale presented herein is the first successively validated scale measuring NFO. The scale not only facilitates a reliable measurement, but also a comprehensive and valid depiction of 
judgments regarding several dimensions of NFO. These dimensions could be used in predicting agenda-setting effects at several levels.

However, beside the establishment of discriminant validity and structural validity, another aim of any scale construction process must be construct validation. There is a widespread agreement in the methodological literature that construct validation is the central concern in measurement (John \& Benet-Martínez, 2000). Construct validation refers to confirming or disconfirming theoretically derived predictions about relations to other constructs that are essential for the theory at hand. Without construct validating a measure, it is not clear whether the observed variables reflect the construct intended to measure or a variety of other constructs or just random error. A first construct validation of the newly developed scale will be presented in Study 3 .

\section{STUDY 3: CONSTRUCT VALIDITY}

As should be apparent from the theoretical discussion, the first hypothesis that is crucial for the NFO construct is a positive relationship between NFO and media use. By definition, people with a high NFO are supposed to pay more attention to the content of the mass media and, therefore, it can be hypothesized that NFO should lead to an increased news media use. This relationship should be equal for all three NFO dimensions. This is the first basic hypothesis in order to establish construct validity.

Furthermore, the prevailing notion throughout almost all previous studies has been that relevance and uncertainty are dimensions of NFO. However, the particular argument made in this article is that both concepts are seen as predictors, not as dimensions. Moreover, we have argued that the concept of relevance may be a stronger indicator for NFO than the concept of uncertainty (McCombs, 2004). This means, in case of low relevance, the NFO is also low, no matter how certain or uncertain a person is. Uncertainty only has an impact in case of high relevance. Speaking in terms of analysis of variance, we would therefore expect an interaction effect of relevance and uncertainty. There should be no main effect of uncertainty. Thus, it can be hypothesized that the perceived relevance of an issue has a positive influence on the NFO. This relationship should be equal for all three NFO dimensions. Furthermore, the hypothesis can be derived that uncertainty has an impact on the NFO towards news media only when the perceived relevance is high. In case of low relevance, there should be no effect of uncertainty.

In establishing construct validity, one additional concept was chosen: the personality construct need for cognition. Need for cognition refers to the tendency of individuals 'to engage in and enjoy effortful cognitive processing' (Cacioppo, Petty, \& Kao, i984, p. 306). Individuals that are high in the need for cognition are highly and intrinsically motivated towards thinking, they tend to enjoy 
FIGURE 2 The relationship between need for cognition, relevance/uncertainty, need for orientation, and media use

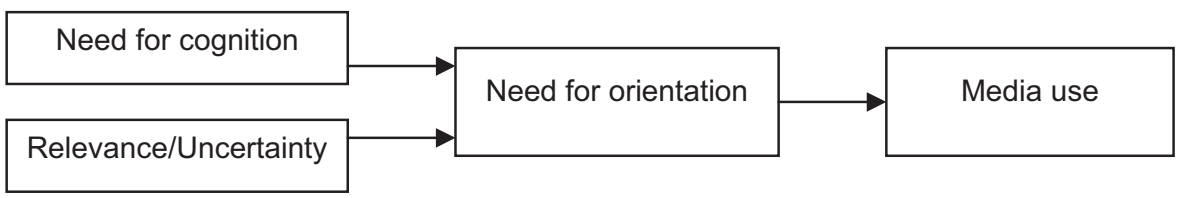

complex cognitive tasks and actively seek and elaborate the information. Or, as described metaphorically by the authors themselves: 'If individuals could be thought of as magnets, information in daily life as fields of iron filings, and the acquisition, scrutiny, and retention of this information as the movement of the filings toward the magnets, then interindividual variations in need for cognition would be the strength of the magnetic fields' (Cacioppo, Petty, Feinstein, \& Jarvis, I996, p. I99). In other words, need for cognition is a motivational measure of a person's craving for cognitive activity. Considering that individuals high in need for cognition are thought to be more likely to expend effort on information acquisition (Cacioppo et al., I996), it can be assumed that high need for cognition people also exhibit a stronger NFO towards the news media. It follows the hypothesis that need for cognition has a positive influence on the NFO towards news media. This relationship should also be equal for all three NFO dimensions.

In sum, the nomological network of validity supporting relations postulated in this study consists of five variables: need for cognition, relevance, uncertainty, $\mathrm{NFO}$, and media use. In structural equation modeling, it is possible to simultaneously test the relations among all those variables in one model (Holbert \& Stephenson, 2002). However, it is rather difficult to test the interaction effect of relevance and uncertainty along with all the other variables in one model. ${ }^{3}$ Therefore, the interaction between relevance and uncertainty will be tested with an additional analysis of variance. The model is depicted in a simplified way in Figure 2.

\section{METHOD}

The third study, which is the second panel-wave of the survey presented in Study 2, took place in August 2002. A total of 484 persons participated in this survey. According to the standard definitions of the American Association for Public Opinion Research (2000), the minimum response rate was $\mathrm{RR}_{\mathrm{I}}=.7 \mathrm{I}{ }^{4}$

\footnotetext{
${ }^{3}$ In order to test this effect, there should be two structural equation models, one for high and one for low relevance. However, this procedure is rather problematic in this case due to the lack of sample size required for these models.

${ }^{4}$ The number of eligible reporting units in the sample in Panel Wave 2 equals the number of complete interviews in Wave $\mathrm{I}$.
} 
In Study 3, all variables needed for the construct validation were measured. ${ }^{5}$ Beside those, all previous measures and procedures are precisely the same as in the previous two studies. The relationship between the variables needed for construct validation will be simultaneously tested with structural equation modeling. Because NFO consists of three factors, there will be three full structural models. ${ }^{6}$

\section{RESUlts}

First of all, it was hypothesized that there is a significant positive effect of relevance and need for cognition on NFO. As the results for the first factor-orientation towards issues - show, this is indeed the case. There is a significant effect of relevance $(\gamma=.28, p<.00 \mathrm{I})$ and a significant effect of need for cognition $(\gamma=.32$, $p<.00 \mathrm{I})$ leading to an amount of explained variance of NFO (i.e. squared multiple correlation, SMC) of 22 percent. Relevance and need for cognition significantly correlate with $r=.19(p<.00 \mathrm{I})$. Moreover, there is also a significant effect of NFO on media use $(\gamma=. \mathrm{I}$ I,$p<.05 ; \mathrm{SMC}=.0 \mathrm{I} 2)$. The whole structural equation model perfectly fits the data $\left(\chi^{2} / \mathrm{df}={ }_{\mathrm{I}} .9 ; \mathrm{GFI}=.98, \mathrm{AGFI}=.96\right.$ and RMSEA $=.04) .{ }^{7}$ The model for the first factor, orientation towards issues, is depicted in Figure 3.

Similar results emerge for the structural equation model for the factor orientation towards facts: There is a significant impact of relevance $(\gamma=. \mathrm{I} 8, p<$. ooI $)$ and need for cognition $(\gamma=.4 \mathrm{I}, p<.00 \mathrm{I})$ on orientation towards facts $(\mathrm{SMC}=.29)$ and also a significant impact of orientation towards facts on the use of news media $(\gamma=. \mathrm{I} \mathrm{I}, p<.05, \mathrm{SMC}=.0 \mathrm{I} 3)$. The fit indices of this structural equation model are also highly satisfactory $\left(\chi^{2} / d f=\mathrm{I} .8 ; \mathrm{GFI}=.98\right.$, AGFI $=.97$ and RMSEA=.04). Finally, the structural equation model $\left(\chi^{2} / d f=\right.$ I.2; GFI $=.99$,

\footnotetext{
${ }^{5}$ Need for cognition was assessed with four items out of the standardized need for cognition questionnaire (Cacioppo, Petty, \& Kao, 1984). These were: 'I find satisfaction in deliberating hard and for long hours,' 'The notion of thinking abstractly is appealing to me,' 'I really enjoy a task that involves coming up with new solutions to problems,' and 'I like tasks that require much thought and mental effort.' The last item is a short form of one original need for cognition item as reported by Cacioppo et al. (1984). The scale proves to be reliable: $\alpha=.68$. Relevance was measured with the pretested item 'Unemployment is the most important issue in German politics.' Because several pretests have shown that this item correlates very highly $(r>.80)$ with an item for personal relevance ('How important is this issue for you personally?'), it was decided not to separate personal from general relevance. Similar to the seminal study by Weaver (1980), uncertainty was measured by a voting intention scale separating respondents who knew which party to vote for from those who did not know. Media use was measured with several questions: First, interviewees were asked to name the three media sources that they used the most for what was going on in the world. Second, for each of the three media sources, they were asked how many days in a week and how many hours a day they used it. These two variables were transformed into one variable that assesses how many hours they use the medium per week. Finally, all three scores were summarized to an unweighted overall score for media usage.

${ }^{6} \mathrm{By}$ convention, the variances of relevance and need for cognition and the coefficients of the regression of the error terms were fixed to one. The exogenous variables were led to correlate. Because relevance was only measured with one variable, its error variance had to be fixed to o.

${ }^{7}$ Indirect effects can be computed by multiplying the $\gamma$-coefficients. For instance, the indirect effect of need for cognition on media use for the factor orientation towards issues is $\gamma=.04$.
} 
FIGURE 3 Structural model for relevance, need for cognition, need for orientation towards issues, and media use

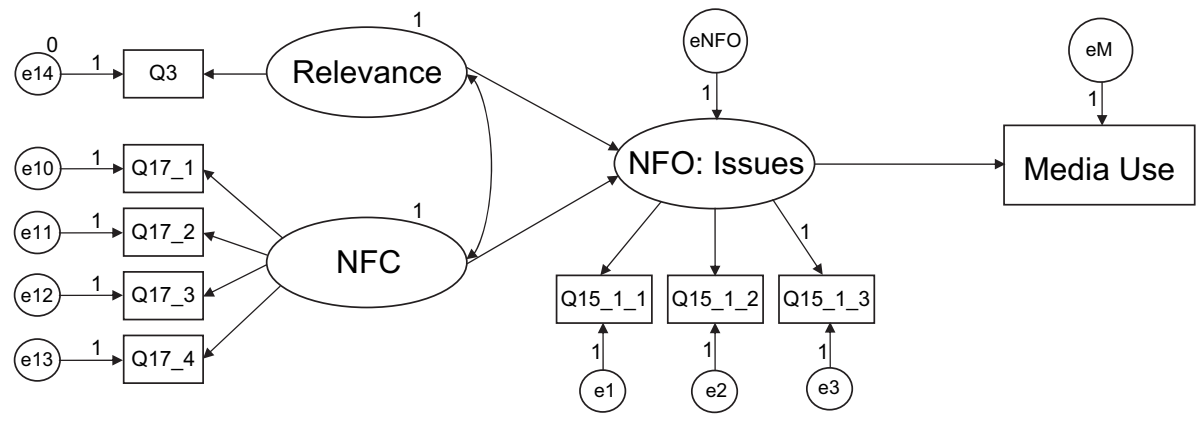

Note: $\mathrm{NFC}=$ need for cognition $; \mathrm{NFO}=$ need for orientation.

$\mathrm{AGFI}=.98$ and $\mathrm{RMSEA}=.02)$ for the NFO towards evaluations reveals the following: Again, relevance $\left(\gamma=. \mathrm{I}_{5}, p<. \mathrm{ooI}\right)$ and need for cognition $(\gamma=.25$, $p<$. oo I) significantly influence orientation towards evaluations (SMC = .Io), which itself influences media use $(\gamma=. \mathrm{I} 9, p<.00 \mathrm{I}, \mathrm{SMC}=.04)$.

Finally, it was assumed that uncertainty has an influence on the NFO only when the perceived relevance of an issue is high. In order to test this hypothesis, an analysis of variance was conducted with a summary score of NFO as the dependent variable and uncertainty and relevance as independent factors. ${ }^{8}$ For the variable relevance, the respondents were divided into three groups by means of an equal percentage split. For the variable uncertainty, only two groups could be distinguished: those with $(n=378)$ and those without $(n=106)$ a voting preference. The results are depicted in Figure 4. As predicted, there is a small but significant interaction effect of uncertainty and relevance, $F(4,478)=5 . \mathrm{I} 2, p=.00 \mathrm{I}, \eta^{2}=.04$; and no main effect of uncertainty, $F(\mathrm{I}, 478)=.27, p=$ n.s., $\eta^{2}=.00 \mathrm{I}$. That means, when there is low relevance, the NFO will be low, independent of uncertainty (high uncertainty, $M=-$. I9, $S D=$. I $5, n=43$; low uncertainty $M=-. \mathrm{I} 8, S D=.07$, $n=\mathrm{I} 73)$. However, when there is high relevance, uncertainty does matter: Respondents with high uncertainty $(M=.47, S D=.84, n=32)$ do have a stronger NFO than those with low uncertainty $\left(M=.22, S D=.99, n=\mathrm{I}_{25}\right)$.

\section{Discussion}

Taken together, these results give convincing support for construct validity. All three dimensions have a significant effect on the use of news media, and need for cognition and relevance are significant predictors of NFO. Furthermore, it could

\footnotetext{
${ }^{8} \mathrm{~A}$ summary score of NFO was used because the relationship between NFO, uncertainty, and relevance is equal for all three dimensions. For pragmatic reasons and due to space limitations, only one analysis of variance is presented here instead of three.
} 
FIGURE 4 Need for orientation as a function of uncertainty and relevance

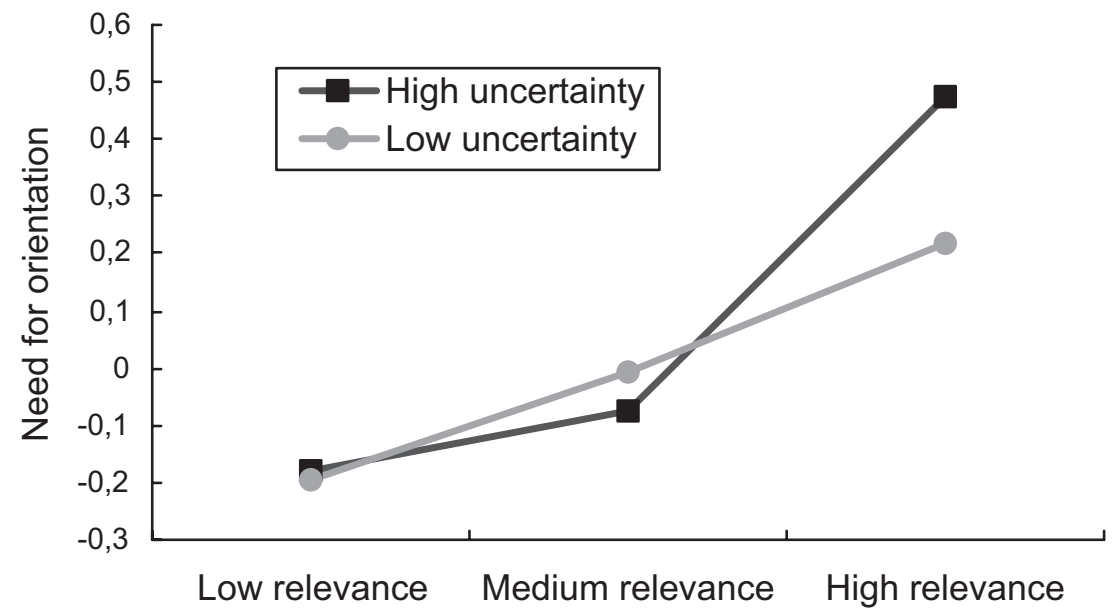

Note: Need for orientation is expressed as z-standardized mean squares.

be shown that uncertainty does influence the NFO of individuals only when relevance is high. However, it is worth noting that the impact of NFO on media use is rather small. One possible explanation for this result is that media use was measured in regard to what is generally going on in the world. In contrast, the NFO items were formulated in regard to one specific issue. General media use is not only explained by several other variables such as time budget or leisure activities, it also depends on how relevant other issues are perceived to be.

\section{GENERAL DISCUSSION}

The need for orientation is indeed a classic. Since the seminal agenda-setting study by McCombs and Shaw (1972), the concept of NFO has accompanied agenda-setting researchers up to this day. Traditionally, NFO has been conceptualized as consisting of two factors, relevance and uncertainty. Although this conceptualization has made significant contributions to the agenda-setting literature, it suffers from some shortcomings. Most importantly, there is little theoretical support that the two components, relevance and uncertainty, equally constitute NFO. Following this train of thought, it becomes evident that both components are predictors, and not actual dimensions of the concept. It follows that NFO was only measured indirectly in all previous studies. Based on this critique, several premises were posited for the operationalization of NFO: First of all, relevance and uncertainty do not constitute the NFO, but-like other variables - they do have an impact on the amount of NFO. Second, the motivation to turn to interpersonal communication should be separated from the NFO towards news media. Third, NFO should be 
measured issue-specifically with several metric items and, finally, a new measure should be developed in a scale construction process that provides evidence for reliability and for factorial, discriminant, and contruct validity.

Based on recent theoretical developments in agenda-setting theory, three dimensions of NFO were posited: NFO towards issues, NFO towards facts, and NFO towards journalistic evaluations. The existence and separability of these dimensions were tested in three studies by several structural equation modeling techniques. The results of the first study showed that two items had to be excluded in order to reach acceptable coefficients. However, discriminant validity could be established by two nested model comparisons. In the second study, this model was then completely validated on another independent random sample. Furthermore, the stability of this result has been tested with alternative estimation techniques. Therefore, the structural validity of the measure could be established. In addition to the establishment of structural and discriminant validity, the results of the third study give convincing support for construct validity. Most importantly, all three dimensions have a significant effect on the use of news media. Another result of the construct validation process is that need for cognition and relevance are significant predictors of NFO. Finally, the last result provides a challenge to the hitherto prevailing assumption that uncertainty and relevance are equal in their impact on NFO. In fact, it could be shown that uncertainty does influence the NFO of individuals only when relevance is high.

Beside the accumulated empirical evidence reported here, however, the question remains of how the results of all three studies should be interpreted in terms of agenda-setting theory? This must, of course, be answered with a good deal of caution. The present study attempts to build upon previous research by differentiating the conditions required for an agenda-setting effect. However, what remains unresolved here is how exactly the new measure works in a real agendasetting study. What is required, then, is a study that examines the relationship between the three dimensions of NFO and several levels of agenda setting. Another line of study should investigate other predictors of NFO. As a whole, construct validation is a continual process that requires the integration of evidence from many different sources. Accordingly, the results reported in the present paper can only be a first contribution to this ongoing endeavor. When interpreting the results for the two predictors uncertainty and relevance, one also has to take into account the unequal group sizes as well as the suboptimal operationalization of both concepts. Last but not least, special attention should be paid to the international validation of the scale. However, the aim of this paper was to describe the development of a reliable and valid measure to assess multiple dimensions of NFO. At least, a valuable result of this re-conceptualization can be an increase in theoretical and methodological scope. It is hoped that the new NFO scale might represent a significant step in specifying a clearer relationship between the NFO, media use and the agenda-setting function of the mass media. 


\section{REFERENCES}

American Association for Public Opinion Research (2000). Standard definitions: Final dispositions of case codes and outcome rates for surveys. Lenexa, Kansas: AAPOR.

Arbuckle, J. L., \& Wothke, W. (I999). Amos 4.o user's guide. Chicago, IL: Small Waters.

Atkin, C. (I973). Instrumental utilities and information seeking. In P. Clark (Ed.), New models for mass communication research (pp. 205-242). Beverly Hills, CA: Sage.

Benton, M., \& Frazier, P. J. (I976). The agenda-setting function of the mass media at three levels of information-holding. Communication Research, 3, 26I-274.

Bollen, K. A. (1989). Structural equations with latent variables. New York: Wiley.

Breckler, S. J. (I990). Applications of covariance structure modeling in psychology: Cause for concern? Psychological Bulletin, 107, 260-273.

Cacioppo, J. T.; Petty, R. E.; Feinstein, J. A., \& Jarvis, W. B. J. (I996). Dispositional differences in cognitive motivation: The life and times of individuals varying in need for cognition. Psychological Bulletin, I I9, I97-253.

Cacioppo, J. T., Petty, R. E., \& Kao, C. F. (I984). The efficient assessment of need for cognition. Journal of Personality Assessment, 48, 306-307.

Clark, L. A., \& Watson, D. (I995). Constructing validity: Basic issues in objective scale development. Psychological Assessment, 7, 309-3 I9.

Curran, P. J., West, S. G., \& Finch, J. (I996). The robustness of test statistics to non-normality and specification error in confirmatory factor analysis. Psychological Methods, I, I6-29.

Dearing, J. W., \& Rogers, E. M. (1996). Agenda-setting. Thousand Oaks: Sage.

Demers, D. P., Craff, D., Choi, Y.-H., \& Pession, B. M. (I989). Issue obtrusiveness and the agenda-setting effects of national network news. Communication Research, ${ }_{1} 6,{ }_{793}-8 \mathrm{I} 2$.

Enders, C. K., \& Bandalos, D. L. (200I). The relative performance of full information maximum likelihood estimation for missing data in structural equation models. Structural Equation Modeling, 8, 430-457.

Erbring, L., Goldenberg, E. N., \& Miller, A. H. (I980). Front-page news and real-world cues: A new look at agenda-setting by the media. American fournal of Political Science, 24, I6-49.

Gabler, S., \& Häder, S. (2002). Idiosyncrasies in telephone sampling-the case of Germany. International Fournal of Public Opinion Research, I4, 339-345.

Gerbing, D. W., \& Hamilton, J. G. (I996). Viability of exploratory factor analysis as a precursor to confirmatory factor analysis. Structural Equation Modeling, 3, 62-72.

Gold, M. S., Bentler, P. M., \& Kim, K. H. (2003). A comparison of maximum-likelihood and asymptotically distribution-free methods of treating incomplete nonnormal data. Structural Equation Modeling, I0, 47-79.

Holbert, R. L., \& Stephenson, M. T. (2002). Structural equation modeling in the communications sciences. Human Communication Research, 28, 53 $\mathrm{I}^{-5} 5^{\mathrm{I}}$.

Hügel, R., Degenhardt, W., \& Weiß, H.-J. (I989). Structural equation models for the analysis of the agenda setting process. European fournal of Communication, 4, I9I-2 Io.

John, O. P., \& Benet-Martínez, V. (200o). Measurement: Reliability, construct validation, and scale construction. In H. T. Reis \& C. M. Judd (Eds.), Handbook of research methods in social and personality psychology (pp. 339-369). New York: Cambridge University Press.

Kohring, M., \& Matthes, J. (2004). Revision und Validierung einer Skala zur Erfassung von Vertrauen in Journalismus [Revising and validating a scale for the measurement of trust in journalism]. Medien ES Kommunikationsmissenschaft, 52, 377-385. 
Kline, R. B. (I998). Principles and practice of structural equation modeling. London: Guilford. López-Escobar, E, Llamas, J. P., \& McCombs, M. (I998). Agenda setting and community consensus: First and second level effects. International fournal of Public Opinion Research, IO, 335-348.

MacCallum, R. C., Roznowski, M., \& Necowitz, L. B. (I992). Model modification in covariance structure analysis: The problem of capitalization on chance. Psychological Bulletin, II I, 490-504.

McCombs, M. E. (2004). Setting the agenda: The nems media and public opinion. Malden, MA: Polity Press.

McCombs, M. E., \& Ghanem, S. I. (200I). The convergence of agenda setting and framing. In S. D. Reese, O. H. Gandy, \& A. E. Grant (Eds.), Framing public life: Perspectives of media and our understanding of the social morld (pp. 67-8I). Mahwah, NJ: Erlbaum.

McCombs, M. E., López-Escobar, E., \& Llamas, J. P. (2000). Setting the agenda of attributes in the 1996 Spanish general election. Fournal of Communication, 50(2), 77-92.

McCombs, M. E., \& Shaw, D. L. (I972). The agenda-setting function of mass media. Public Opinion Quarterly, 36, I76-187.

McCombs, M. E., \& Weaver, D. H. (I973). Voters' need for orientation and use of mass communication. Presented at the annual conference of the International Communication Association. Montreal, Canada.

McCombs, M. E., \& Weaver, D. H. (1985). Toward a merger of gratifications and agenda setting research. In K. E. Rosengren, L. A. Wenner, \& P. Palmgreen (Eds.), Media gratifications research (pp. 95-108). Beverly Hills, CA: Sage.

Muthén, B., \& Kaplan, D. (I992). A comparison of some methodologies for the factor analysis of non-normal Likert variables: A note on the size of the model. British Fournal of Mathematical and Statistical Psychology, 45, I9-30.

Noar, S. M. (2003). The role of structural equation modeling in scale development. Structural Equation Modeling, I0, 622-647.

Peter, J. (2003). Country characteristics as contingent conditions of agenda setting: The moderating influence of polarized elite opinion. Communication Research, 30, 683-7 I 2.

Rössler, P. (I999). The individual agenda-designing process. Communication Research, 26, 666-70o.

Rössler, P., \& Schenk, M. (2000). Cognitive bonding and the German reunification: Agenda-setting and persuasion effects of mass media. International Fournal of Public Opinion Research, I2, 29-47.

Scheufele, D. A. (I999). Framing as a theory of media effects. Fournal of Communication, 49(I), I03-I22.

Scheufele, D. A. (2000). Agenda-setting, priming, and framing revisited: Another look at cognitive effects of political communication. Mass Communication E Society, 3, 297-3 6 .

Schönbach, K., \& Weaver, K. (I985). Finding the unexpected: Cognitive building in a political campaign. In S. Kraus \& R. M. Perloff (Eds.), Mass media and political thought: An information-processing approach (pp. I 57-I 76). Beverly Hills, CA: Sage.

Shaw, D. L., \& McCombs, M. E. (I977). The emergence of American political issues: The agenda-setting function of the press. St. Paul: West Publishing. 
Shaw, D. L., McCombs, M. E., Weaver, D. H., \& Hamm, B. J. (I999). Individuals, groups, and agenda melding: A theory of social dissonance. International fournal of Public Opinion Research, II, 2-24.

Swanson, D. L. (I988). Feeling the elephant: Some observations on agenda-setting research. Communication Yearbook, II, 603-6I9.

Takeshita, T. (2006). Current critical problems in agenda-setting research. International Journal of Public Opinion Research, I8, 275-296.

Tashakkori, A., \& Teddlie, C. (I998). Mixed methodology-combining qualitative and quantitative approaches. London: Sage.

Wanta, W. (I997). The public and the national agenda: How people learn about important issues. Mahwah, NJ: Erlbaum.

Wanta, W., \& Wu, C.-C. (I992). Interpersonal communication and the agenda-setting process. Fournalism Quarterly, 69, 847-855.

Weaver, D. H. (I977). Political issues and voter need for orientation. In D. L. Shaw \& M. E. McCombs (Ed.), The emergence of American public issues (pp. 107-120). St. Paul, MN: West.

Weaver, D. H. (I980). Audience need for orientation and media effects. Communication Research, 3, 36I-376.

Weaver, D. H., Graber, D. A., McCombs, M. E., \& Eyal, C. H. (I98I). Media agendasetting in a presidential election: Issues, images, and interest. New York: Praeger.

Weaver, D. H., McCombs, M. E., \& Shaw, D. L. (2004). Agenda-setting research: Issues, attributes, and influences. In L. L. Kaid (Ed.), The handbook of political communication research (pp. 257-283). Mahwah, NJ: Erlbaum.

Wegener, D. T., \& Fabrigar, L. R. (2000). Analysis and design for nonexperimental data: Addressing causal and noncausal hypotheses. In H. T. Reis \& C. M. Judd (Eds.), Handbook of research methods in social and personality psychology (pp. 4I2-450). New York: Cambridge University Press.

West, S. G., Finch, J. F., \& Curran, P. J. (I995). Structural equation models with nonnormal variables. Problems and remedies. In R. H. Hoyle (Ed.), Structural equation modeling: Concepts, issues, and applications (pp. 56-75). Thousand Oaks, CA: Sage.

Winter, J. P. (I98I). Contingent conditions in the agenda-setting process. In G. C. Wilhoit \& H. deBock (Eds.), Mass communication reviem yearbook 2 (pp. 235-243). Beverly Hills, CA: Praeger.

Yagade, A., \& Dozier, D. M. (I990). The media agenda-setting effect of concrete versus abstract issues. Fournalism Quarterly, 67, 3-10.

\section{BIOGRAPHICAL NOTE}

Jörg Matthes is a Ph.D. student at the Institute of Mass Communication and Media Research, University of Zürich, Switzerland. His research focuses on the process of public opinion formation, media effects, and trust in news media.

Please address correspondence to Jörg Matthes, IPMZ — Institute of Mass Communication and Media Research, University of Zürich, Andreasstrasse I5, 8050 Zürich, Switzerland, e-mail: j.matthes@ipmz.unizh.ch 